\title{
Segment-specific regulation of epididymal gene expression
}

\author{
Petra Sipilä ${ }^{1}$ and Ida Björkgren² \\ ${ }^{1}$ Department of Physiology and Turku Center for Disease Modeling, Institute of Biomedicine, University of Turku, \\ Turku, Finland and ${ }^{2}$ Department of Molecular and Cell Biology, University of California, Berkeley, California, USA
}

Correspondence should be addressed to P Sipilä; Email: petra.sipila@utu.fi

\begin{abstract}
The epididymis is necessary for post-testicular sperm maturation. During their epididymal transit, spermatozoa gain ability for progressive movement and fertilization. The epididymis is composed of several segments that have distinct gene expression profiles that enable the establishment of the changing luminal environment required for sperm maturation. The epididymal gene expression is regulated by endocrine, lumicrine, and paracrine factors in a segment-specific manner. Thus, in addition to its importance for male fertility, the epididymis is a valuable model tissue for studying the regulation of gene expression. This review concentrates on recent advances in understanding the androgen, small RNA, and epigenetically mediated regulation of segment-specific gene expression in the epididymis.

Reproduction (2016) 152 R91-R99
\end{abstract}

\section{Introduction}

The epididymis is a long (approximately $1.2 \mathrm{~m}$ in mice and $6 \mathrm{~m}$ in humans) convoluted tubule connecting the efferent ducts to vas deferens. It is derived from the Wolffian duct (WD), with the exception of the most proximal part in rodent epididymis, which is suggested to form from the mesonephric tubules along with the efferent ducts (Reviewed in Robaire et al. 2006, Shaw \& Renfree 2014). In adults, the epididymal epithelium lining the tubule is a pseudostratified columnar epithelium composed of different cell types, namely principal, basal, clear/ narrow, and apical cells. The tissue is divided into three main segments: caput, corpus, and cauda, which are further divided into several subsegments by connective tissue septae (Abou-Haila \& Fain-Maurel 1984). Further, in rodents, the most proximal part of the epididymis, initial segment (IS), can be separated from the rest of the caput and forms the fourth main segment. In each of the segments, the morphology of the epithelium and the diameter of the lumen differ from other segments. In the IS, the epithelium is tall, and the luminal diameter is small, and from thereon, toward more distal epididymal regions, the epithelial cell height diminishes and the luminal diameter increases (Fig. 1).

In addition to the morphology of the epithelium, the epithelial cells are functionally different from epididymal segments that are regulated by a very tightly controlled gene expression. Many genes exhibit cell type and segment-specific expression patterns, where expression can be restricted to one particular subsegment. Additionally, several gene families, for example, prostate and testis expression (Pate, Turunen et al. 2011) and wingless-type MMTV integration site family (Wnt, Koch et al. 2015), display distinct expression patterns along the tissue; certain family members are restricted to specific epididymal regions, whereas other members are present in the whole tissue (Fig. 2). Moreover, segmentspecific gene expression is regulated differentially in distinct segments, for example, most caput-specific genes are under androgen regulation, whereas most IS-specific genes require additional lumicrine factors (i.e. factors coming from testis along with the luminal fluid) for full expression (Sipilä et al. 2006). Furthermore, some genes are regulated differentially in different epididymal regions. For example, for gamma-glutamyl transpeptidase $(G g t)$, multiple mRNAs are produced in the epididymis and regulated in a segment-specific manner. Ggt mRNA IV expressed in the IS, corpus, and cauda is regulated by lumicrine factors in the IS, but not in the corpus and cauda, whereas mRNAs II and III expressed in all epididymal regions are under the control of androgens (Palladino \& Hinton 1994). This precise control of epididymal gene expression is thought to provide the basis for epididymal sperm maturation. In each of the epididymal segments, a specific set of proteins is expressed and secreted into the luminal fluid creating the changing luminal environment required for sperm maturation in a sequential manner.

Spermatozoa produced in the testis need to go through epididymal maturation to obtain the ability to move progressively forward and full fertilization capacity. During this post-testicular maturation, the interaction with luminal proteins secreted by epididymal epithelial cells results in constant remodeling of the sperm cell 


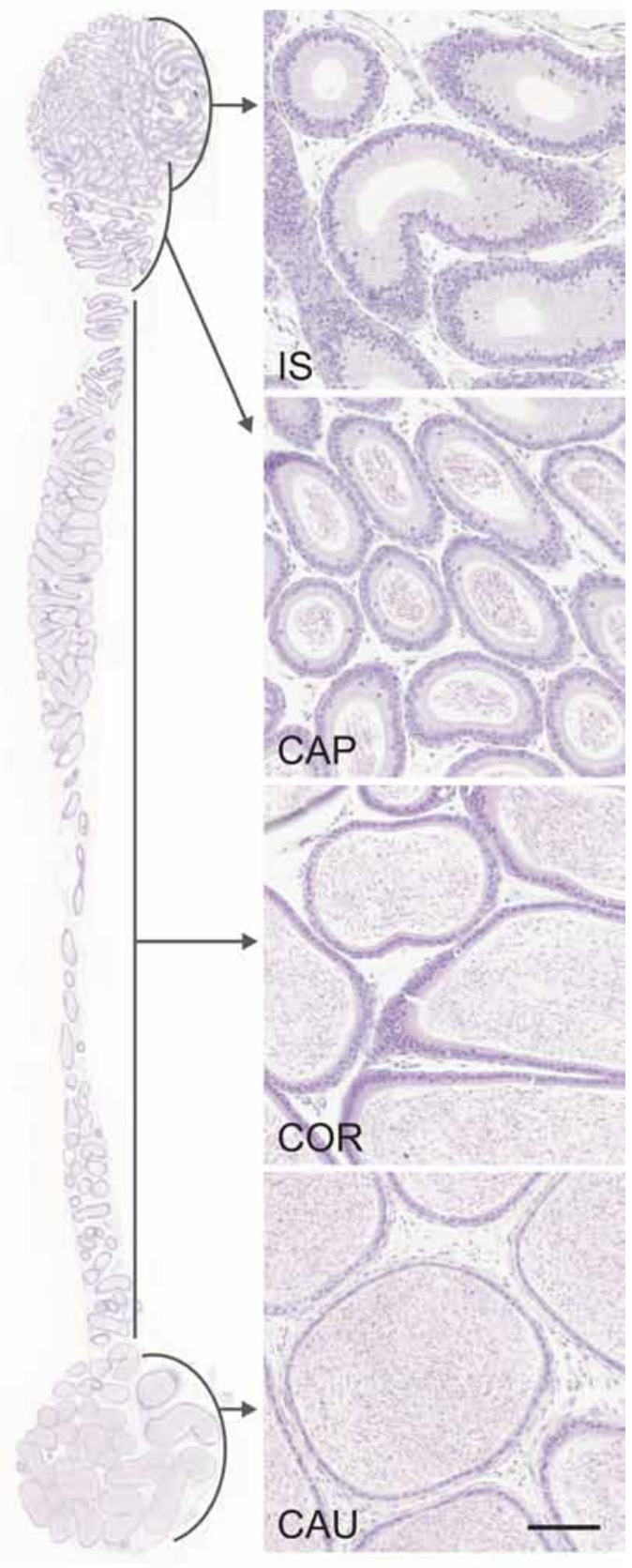

Figure 1 Histology of the adult mouse epididymis. Hematoxylin and eosin staining of wild-type $\mathrm{C} 57 \mathrm{Bl} / 6 \mathrm{~N}$ mouse epididymal sections. CAP, caput; CAU, cauda; COR, corpus; IS, initial segment. Scale bar $100 \mu \mathrm{m}$.

membrane, with attachment and shedding of proteins in a sequential manner (Reviewed in Dacheux \& Dacheux 2013). In addition, epididymal membrane vesicles, epididymosomes, have been shown to transfer proteins and lipids to the spermatozoa, thus changing, for example, the sperm lipid content during epididymal maturation (Saez et al. 2011, Sullivan \& Saez 2013). Interesting new results reveal how epididymal Wnt signaling controls sperm maturation via epididymosomes by affecting target protein phosphorylation and global protein

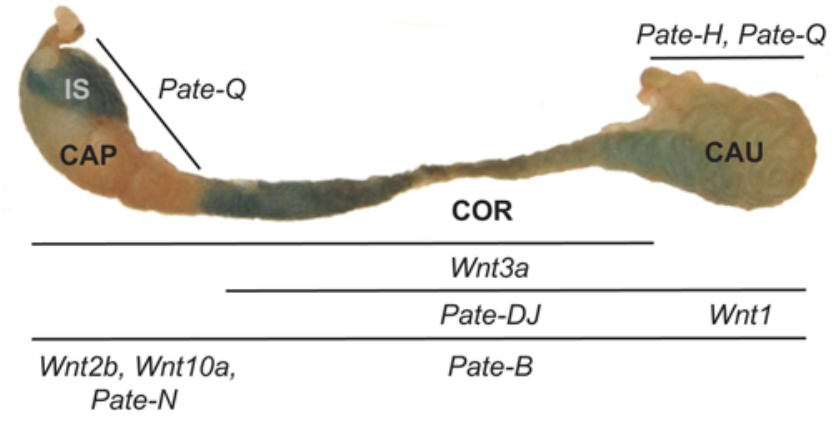

Figure 2 Segmental expression of selected prostate and testis expression (Pate) and wingless-type MMTV integration site family $(W n t)$ members in the mouse epididymis. The segments are visualized by $\mathrm{X}$-gal staining. Regions with expression are marked with line and the name of the gene is written next to the segment with highest expression level. More detailed information about the expression patterns are Pate (Turunen et al. 2011) and Wnt (Koch et al. 2015). CAP, caput; CAU, cauda; COR, corpus; IS, initial segment.

ubiquitination in sperm (Koch et al. 2015). Furthermore, it seems plausible that the epididymis transfers the information about epigenetic changes caused by environmental factors, such as paternal diet, to sperm via epididymosomal transport of tRNA fragments (Sharma et al. 2016). As the correct order of sperm membrane modifications is important for surface architecture, it is of utmost importance that epididymal gene expression is tightly regulated. How is this beautifully synchronized gene expression controlled? The aim of this review is to provide an overview of recent findings in this field of research. This review mainly focuses on small RNA/ epigenetic and androgen regulation where exciting progress has been made. Moreover, recent scientific discoveries revealing an overlap of the above-mentioned regulatory mechanisms are discussed.

\section{Physical barrier}

Connective tissue septa, dividing epididymal subsegments, are important in the regulation of paracrine signaling within the epididymis. Experiments using dyes and radiolabeled molecules of varying molecular weight demonstrated the ability of septa to restrict the movement of molecules, with a size range of most proteins, between segments (Turner et al. 2003). Inter-segmental microperfusions of several growth factors (epidermal growth factor, EGF; vascular endothelial growth factor, VEGFA; and fibroblast growth factor 2, FGF2) into the rat epididymis supported these previous findings. All the factors increased phosphorylation of mitogen-activated protein kinase (MAPK) only in the segment where they were injected and not in the adjacent segment, separated by septa (Tomsig et al. 2006). Thus, although being composed of a single convoluted tubule, the structural organization of the epididymis allows local paracrine signaling to occur in a segment-specific manner. 


\section{Epigenetic mechanisms}

Epigenetic control of gene expression refers to the regulation of gene activity that does not involve alterations in the DNA sequence. The most studied epigenetic mechanisms are histone modifications and DNA methylation. Methylation and demethylation of histone 3 lysines affect the accessibility of chromatin and thus transcription (Zhou et al. 2011). Even though widely studied in many other organs, the involvement of histone modifications controlling epididymal gene expression has not been studied. However, a recent knock out of absent, small, or homeotic discs-1 like (Ash1/) gene implied that this epigenetic mechanism is an important controller also in the epididymis (Brinkmeier et al. 2015). ASH1L is a histone methyltransferase shown to associate with Hox genes, with knock down causing reduced histone 3 lysine $4(\mathrm{H} 3 \mathrm{~K} 4)$ trimethylation at Hoxa10 gene in vitro (Gregory et al. 2007). Knocking out Ash1/ led to segment-specific down-regulation of Hox gene expression and morphological transformation from corpus to caput and from vas deferens to cauda, similar to that seen in Hoxa10 and Hoxa11 knockout mice (Brinkmeier et al. 2015). The lack of Ash1/ could cause a reduction in activating histone mark $\mathrm{H} 3 \mathrm{~K} 4 \mathrm{me} 3$ and repression of target genes. Nonetheless, further studies are required to demonstrate the role of histone modifications in the epididymis.

DNA methylation is an important regulator of fundamental biological processes such as X-chromosome inactivation and genomic imprinting. In DNA methylation, a methyl group is covalently attached to the $\mathrm{C} 5$ position of a cytosine residue, forming 5 -methylcytosine $(5 \mathrm{mC})$ by DNA methyltransferase (DNMT) enzymes (Kohli \& Zhang 2013, Sadakierska-Chudy et al. 2015). Generally, DNA methylation is associated with transcriptional repression. However, for example, genome-wide analysis of human DNA methylation in different tissues revealed a group of intragenic tissue-specific methylation sites, where methylation was positively correlated with the expression of the host gene (Straussman et al. 2009). Previously, DNA methylation was considered a stable and persistent mark; nevertheless, recent findings have demonstrated that methylation is a reversible and dynamic process (Sadakierska-Chudy et al. 2015). DNA demethylation occurs via passive process during replication but also actively via oxidation by ten-eleven translocation (TET) family enzymes (Kohli \& Zhang 2013, SadakierskaChudy et al. 2015). For further regeneration of unmodified cytosine residues, three putative pathways have been suggested: passive dilution during replication, removal of the oxidized substituent, or the modified nucleotide by DNA repair-mediated mechanisms. The establishment of DNA methylation patterns has a significant contribution in the development and differentiation of different tissues and thus in controlling tissue and cell-specific expression patterns.

\section{Epididymal DNA methylation}

DNA methylation in the epididymis has been analyzed only in a few studies. In the newborn and 7-day-old rat epididymis, cyclin D1 promoter methylation was found to correlate with expression levels; in newborns with high cyclin D1 expression, the promoter area was unmethylated, whereas in 7-day-old rats, cyclin D1 expression levels came down and methylation of the promoter area increased (Darwanto et al. 2008). However, at day 7 , there is a marked difference in cyclin D1 expression levels between different epididymal segments, with high expression levels in the cauda epididymis (Wang \& Kumar 2012), which was not taken into account in the study by Darwanto et al. (2008). As the epididymal cyclin D1 expression patterns change during postnatal development, and result in a segment-specific expression in adults (Wang \& Kumar 2012), it would be interesting to study the promoter methylation in a more detailed manner.

A study on male piglets discovered one intragenic $\mathrm{GpC}$ site whose methylation status correlated with estrogen receptor 1 (ESR1) expression. The epididymis with high ESR1 expression levels had 200\% higher methylation levels of that specific GpC site than heart tissue with low ESR1 expression levels (Fürst et al. 2012). Interestingly, that GpC site harbored a putative transcriptional repressor TG-interacting factor 1 (TGIF) binding site. TGIF has been previously shown to interact with histone deacetylase 1 (HDAC1) leading to chromatin condensation and repression of transcription (Fürst et al. 2012). Accordingly, a reduced histone H3 presence at the specific intragenic, highly methylated $\mathrm{GpC}$ site in the epididymis was confirmed by chromatin immunoprecipitation, suggesting a loose chromosomal structure around that area (Fürst et al. 2012).

For Rhox 5 homeobox gene, it was shown that CpG islands in the Rhox 5 proximal promoter were differentially methylated in the epididymal segments of mice. Further, methylation correlated with the expression pattern of Rhox 5 during epididymal development. CpG islands in the promoter area were hypermethylated in caput of 11- and 25-day-old animals when Rhox 5 is hardly expressed and were demethylated as Rhox5 expression increased at 30 days of age. In contrast, in corpus and cauda where Rhox 5 is not expressed, the methylation levels were not reduced during postnatal development (Bhardwaj et al. 2012). The data also suggested that androgen receptor (AR) occupancy at the androgen response element (ARE) sites in the Rhox 5 promoter region was dependent on DNA methylation status in that region (Bhardwaj et al. 2012). On the other hand, recent genome-wide methylation status analysis from rats did observe differentially methylated genomic areas in distinct epididymal regions, but the methylation status of genes did not correspond to the expression pattern of those genes. In addition, the rat 
Rhox 5 promoter was not found to be methylated in that study (Chu et al. 2015). Thus, further studies are required to obtain a better understanding of the species differences and the overall role of segment-specific DNA methylation in the epididymis.

\section{Small RNAs}

The majority of the mammalian genome is transcribed, ranging from $63 \%$ in mice (Carninci et al. 2005) to a staggering estimate of $93 \%$ of the human genome that may be transcribed (ENCODE Project Consortium et al. 2007). Furthermore, it was estimated that less than half of transcribed RNA code proteins and the rest are the so called non-coding RNAs (ncRNA; Carninci et al. 2005). ncRNAs include, for example, long ncRNAs and small RNAs such as microRNA (miRNAs), endogenous small interfering RNAs (endo-siRNAs) and PIWI-interacting RNAs (piRNAs). High-throughput small RNA sequencing studies have identified piRNA and miRNA in the epididymis (Yan et al. 2011, Li et al. 2012). Although the existence of piRNAs in mammalian somatic cells is still questionable (Ross et al. 2014), the presence of miRNAs and their functions in the cells have been studied extensively and are currently quite well understood.

\section{miRNAs}

miRNAs are transcribed by RNA polymerase II and cleaved by the RNase III enzyme, DROSHA, producing individual pre-miRNAs. EXPORTIN 5 exports premiRNAs into the cytoplasm, where another RNase III enzyme, DICER1, cleaves the loop structure, producing mature miRNA. One miRNA strand is loaded into the RNA-induced silencing complex (RISC) where it directs translational repression or cleavage of mRNA targets (Fig. 3, reviewed recently in Hammond 2015). miRNAs mainly target 3 '-untranslated regions (3'-UTRs) of mRNAs. As the target sequence is often not perfectly complementary to the miRNA sequence, each miRNA potentially targets hundreds of genes/mRNAs and each mRNA has several regulatory miRNAs (Selbach et al. 2008). Thus, the miRNAs form a regulatory network providing yet another level of complexity to the regulation of gene expression.

After the discovery of miRNAs, an atlas of miRNA expression patterns in different tissues of several different species was generated (Landgraf et al. 2007). Using the data generated in the miRNA Atlas, it was further shown that the human and non-human primate-specific X-chromosomal miR-888 cluster of six miRNAs is predominantly expressed in the epididymis and other male reproductive tissues (Li et al. 2010). Comparison of epididymal miRNA profiles between humans (Belleannee et al. 2012a,b), mice (Nixon et al. 2015a,b), and rats (Chu et al. 2015) revealed a

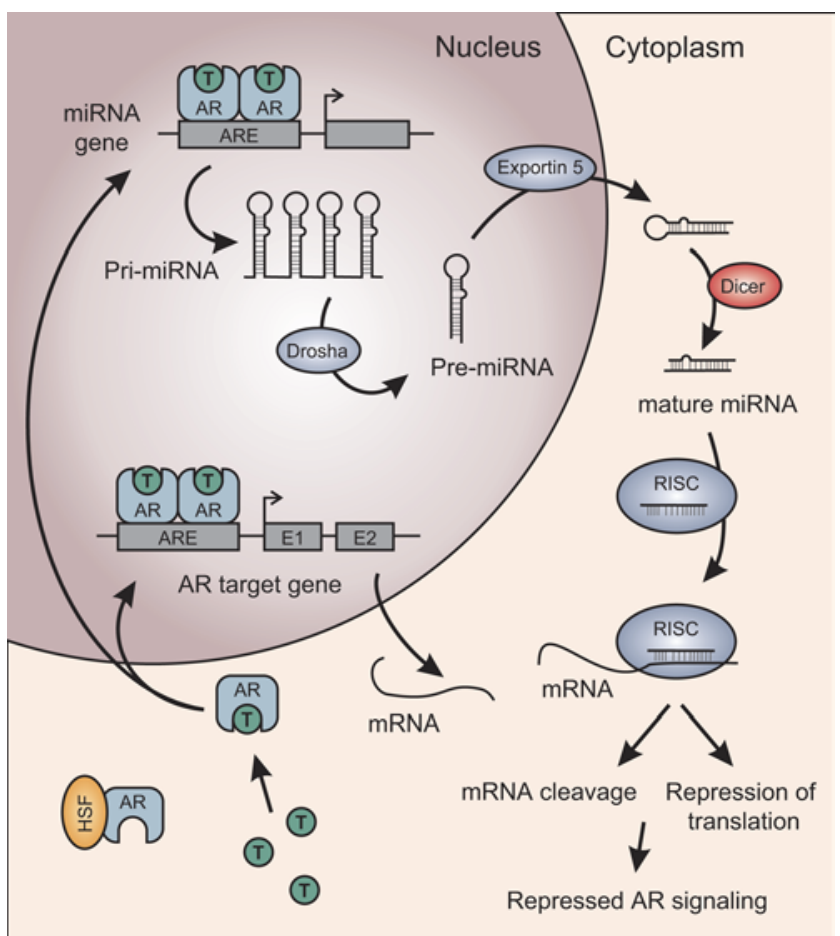

Figure 3 Interactions of androgen and miRNA regulatory pathways. Ligand-activated androgen receptor (AR) moves into nucleus where it binds to the regulatory areas of target genes and miRNAs. Mature miRNAs control AR activity by targeting mRNAs of AR target genes. ARE, androgen response element; HSF, heat-shock factor; RISC, RNA-induced silencing complex; T, testosterone.

surprisingly low conservation of miRNAs across species (Fig. 4). Intriguingly, a majority of conserved miRNAs were found to be expressed throughout the epididymis, indicating a general housekeeping function of miRNAmediated regulation (Nixon et al. 2015a,b). Comparable analyses of epididymal miRNA and mRNA profiles have been performed to identify miRNA target genes in the different regions of the human and rat epididymis at different ages (Zhang et al. 2010, Wang \& Ruan 2010a,b, Belleannee et al. 2012a,b). Those studies identified several putative targets known to affect fertility. In the human epididymis, claudin 10 (Cldn10) and estrogenrelated receptor Gamma (Esrrg) were confirmed to be the targets of miR-145 and miR-892b in vitro using a luciferase reporter system (Belleannee et al. 2012a,b), whereas RAS p21 protein activator 1 (Rasa1) and $\beta$-catenin were shown to be miR-335 and miR-200a targets in rats respectively (Wang \& Ruan 2010a,b, Wu et al. 2012). In mouse epididymis, in vitro reporter assays confirmed that mitogen-activated protein kinase 14 (Mapk14) is a target for miR-200c and forkhead box O1 (Foxo1) for miR-486 (Nixon et al. 2015a,b).

The overall importance of miRNAs to the epididymal functions and sperm maturation was shown by specific deletion of Dicer1 in the proximal mouse epididymis (Björkgren etal. 2012, 2015). In the Defb411Cre;Dicer $1^{\text {fl/fl }}$ 

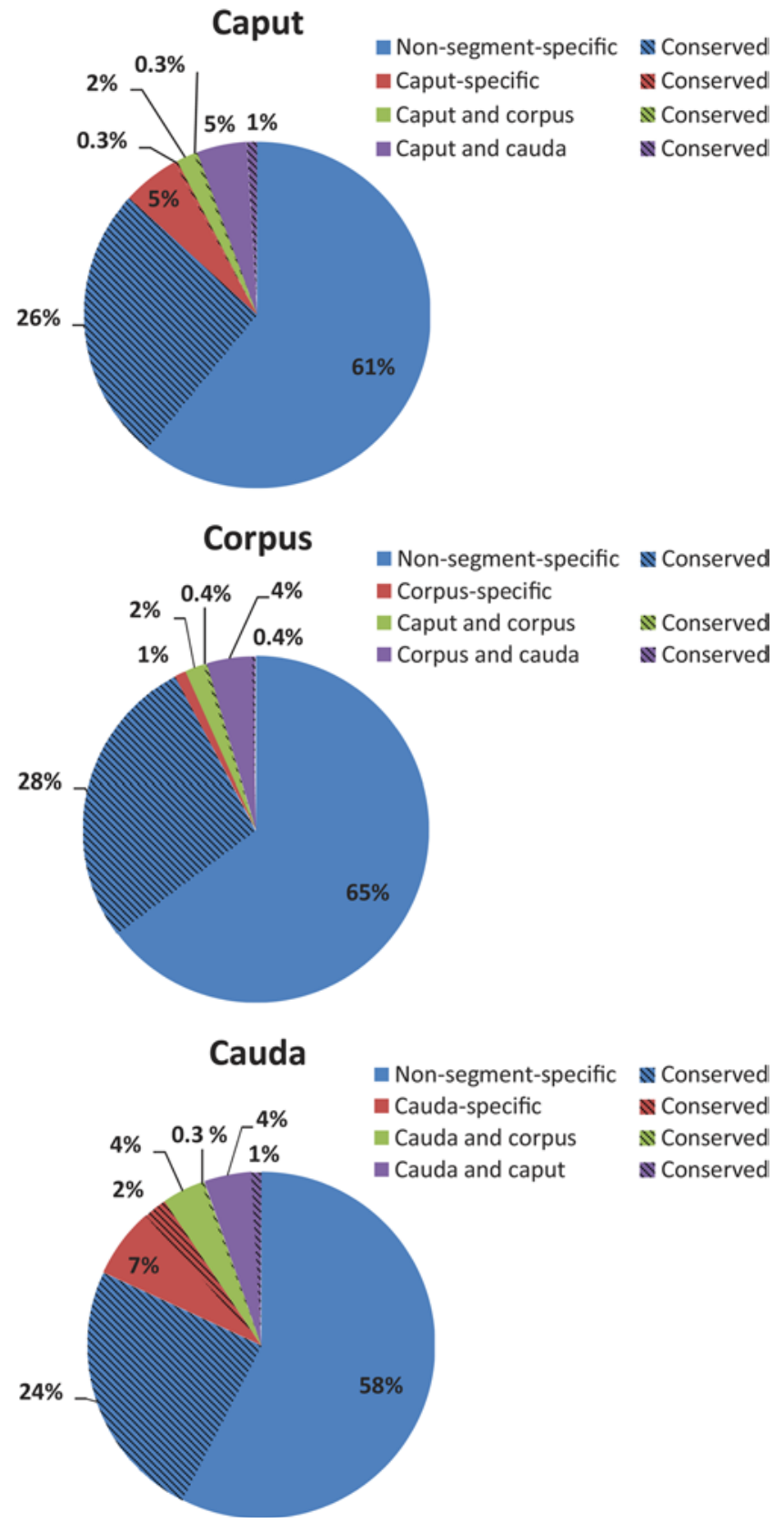

Figure 4 Segmental expression of miRNAs in the mouse epididymis. Pie charts from caput, corpus, and cauda showing percentages of segmental miRNAs from total miRNAs present in that given segment. The shading marks represent the percentage of miRNAs that are conserved across mice, rats, and humans. Due to different analysis methods used, the two mature miRNAs, $-3 p$ and $-5 p$, were not distinguished. Note that all the conserved miRNAs showing segment specificity in the mouse epididymis are uniformly expressed in all the epididymal regions of rat and human epididymis. For the full data sets, readers are referred to the following original articles: mice, Nixon et al. (2015a,b); rats, Chu et al. (2015); humans, Belleannee et al. $(2012 a, b)$.

mouse model, the lack of Dicer 1 caused dedifferentiation of the epithelium with imbalanced sex steroid receptor expression and defects in lipid homeostasis in the epithelium, subsequently causing changes in the lipid constitution of the sperm membrane and male infertility (Björkgren \& Sipilä 2015). The direct effects of individual epididymal miRNAs have been assessed for two miRNAs. miR-7578 was shown to regulate both mRNA and protein levels of early growth response 1 (Egr 1 ) gene and thus acts as a negative regulator of inflammatory responses (Zhang et al. 2013). miR-29a was shown to regulate epididymal cell proliferation during postnatal epididymal development in rats by targeting nuclear autoantigenic sperm protein (Nasp, Ma et al. 2012), which is known to control cell cycle progression via binding to histones and affecting chromatin assembly (Wang et al. 2008). Further, it was shown that miR-29a is directly regulated by androgens and it was suggested to form a regulatory circuit with AR by targeting two known AR regulators, insulin-like growth factor 1 (IGF1) and p53 (Ma et al. 2013). Transgenic mice overexpressing miR-29a had significantly smaller epididymides, which was suggested to be due to repressed AR signaling (Ma et al. 2013). However, as miR-29a was previously shown to repress cell proliferation (Ma et al. 2012), the observed phenotype could be due to a proliferative defect of the epithelium.

In addition to controlling epididymal functions in a given cell, miRNAs have been proposed to mediate intercellular communication in a paracrine-like fashion via transfer by epididymosomes, membrane vesicles that are released from epididymal epithelial cells via apocrine secretion (Hermo \& Jacks 2002). Distinct miRNA populations have been found from the epididymosomes from different epididymal regions of the bovine and human epididymis (Belleannee et al. $2013 a, b)$. Studies on bovine demonstrated that miRNAs present in the epididymosomes differ from those of the surrounding epithelial cells, suggesting that miRNAs are selectively released into epididymosomes (Belleannee et al. 2013a,b). Furthermore, epididymosomes obtained from the proximal epididymis were shown to bind to the epithelial cells from distal epididymis in vitro (Belleannee et al. 2013a,b). Similar mechanisms have been demonstrated in other tissues as well, suggesting a general mode of intercellular regulation (reviewed in Belleannee 2015). As epididymosomes have been shown to transfer proteins and lipids to the spermatozoa present in the epididymal lumen (Sullivan \& Saez 2013), it is conceivable that miRNAs needed in the zygote may be transferred into spermatozoa during the epididymal maturation. This hypothesis is supported by three recent studies. Exciting work by Sharma et al. (2016) demonstrated that the tRNA fragment (tRF) content of spermatozoa changes during epididymal maturation. The tRF load of epididymosomes from the cauda epididymis correlated with that of caudal sperm, and further, purified caudal epididymosomes were able to deliver cauda-enriched tRFs to sperm isolated from the caput region. Sperm tRFs were suggested to be the epigenetic 
factor transferring intergenerational inheritance (Chen et al. 2016, Sharma et al. 2016). Moreover, Nixon et al. $(2015 a, b)$ showed that also the miRNA profile of mouse spermatozoa changes during epididymal transit from caput to cauda, and in a study by Johnson et al. (2015), long (>100 nt) RNA content of spermatozoa was shown to comprise extracellular-vesicle-associated RNA, possibly incorporated into spermatozoa during epididymal transit.

\section{Regulation via steroid hormones}

Steroid hormones transmit their signal via nuclear receptors. In the absence of ligand, the receptors are located in the cytoplasm bound to heat-shock proteins. Upon ligand binding, the receptors undergo a conformational change facilitating recruitment of coactivator proteins and the ligand-receptor complex is shuttled to the nucleus. In the nucleus, classical steroid receptors form homodimers and bind to the hormone response elements of target genes to regulate gene transcription (Fig. 3). Steroid hormones known to regulate epididymal gene expression are androgens and estrogens. Further studies are needed to reveal the significance of recent findings of active glucocorticoid signaling in the rat epididymis (Silva et al. 2011) and vitamin D nuclear receptor and its metabolizing enzymes in the human epididymis (Blomberg Jensen et al. 2010) for epididymal gene expression.

Testosterone enters to the epididymis via blood circulation but also through the efferent ducts. Inside the epididymal epithelial cells, testosterone is reduced to more potent dihydrotestosterone (DHT) by $5 \alpha$-reductases (Robaire \& Hamzeh 2011). The main source of estrogen in males is the testis; however, the additional presence of P450 aromatase in spermatozoa provides a local source of estrogen in the epididymis (Reviewed in Hess 2014). As the estrogen action in the epididymis was recently reviewed (Hess et al. 2011, Hess 2014), this review will focus on androgen regulation. Of note, however, is the notion that the correct balance between androgen and estrogen levels might be of importance for maintaining epididymal functions. Observed imbalance in androgen-estrogen signaling might partly explain the epithelial cell phenotype, diminished cell height, increased proliferation, and regression to an undifferentiated state, in the mouse model lacking DICER1 in the proximal epithelium (Björkgren et al. 2012). The importance of correct hormonal balance has been noted in the prepubertal development of the reproductive tract in male rats, where changes in the testis and reproductive tract morphology induced by exposure to estrogens were shown to result from a combination of high estrogen and low androgen action (Williams et al. 2001). Furthermore, low androgen:estrogen ratio seems to be important for Leydig tumor cell proliferation and in regulating immune and inflammatory responses (Cutolo et al. 2002, Maris et al. 2015).

\section{Androgens}

It has long been known that the development and maintenance of the epididymis is dependent on androgens. During embryonal development, androgens are necessary for WD stabilization and further development. However, it was recently shown using conditional $\mathrm{Ar}$ knockout mouse models that androgen signaling via $A R$ in the WD epithelium is not required for stabilization nor subsequent elongation and coiling of WD/epididymis. In contrast, AR in the mesenchyme surrounding the WD epithelium is essential for the above-mentioned processes (Murashima et al. 2011). Epithelial-mesenchymal interactions are a requisite for several developmental processes (Ribatti \& Santoiemma 2014). The above-mentioned results, along with earlier studies, for example, on leucine-rich repeat-containing G protein-coupled receptor 4 (Igr4, Mendive et al. 2006) and inhibin beta-A (Inhba, Tomaszewski et al. 2007) demonstrate the need for epithelial-mesenchymal interactions in the development of WD derivatives as well. However, a considerable amount of research is needed before the reciprocal signaling between the WD epithelium and the surrounding mesenchyme is better characterized. The final differentiation of the epididymis, formation of epithelial cell types, and segmentation occurs after birth and in contrary to the embryonal development requires epithelial AR (Krutskikh et al. 2011, Murashima et al. 2011, O'Hara et al. 2011).

Previous studies have reported a wide variety of epididymal androgen-regulated genes in different species (reviewed in Belleannee et al. 2012a,b). These early studies revealed interesting patterns of androgen regulation of the epididymal gene expression, but did not provide any explanations for the segment-specific nature of the regulation. Specificity of spatiotemporal androgen regulation in different tissues is achieved by differential usage of coregulators, collaborating transcription factors and pioneer factors. Currently, there are over 160 AR coregulators known, some of which act as coactivators or corepressors, and some can act as both activators/repressors depending on cellular context (Heemers \& Tindall 2007). Several known androgen coregulators were identified in the mouse epididymal array data. Some coregulators show segment enrichment in their expression, suggesting that these factors may contribute to the segment-specific responses (Sipilä et al. 2011).

Of all AR coregulators, only the role of forkhead box A2 (Foxa2) transcription factor in mediating androgen action in the epididymis has been studied in detail. Foxa2 is expressed in the corpus and cauda, where it was found to suppress androgen activation of lipocalin 5 (Lcn5). The low levels of Foxa2 in the caput allowed Lcn5 transcription to be activated by AR (Yu et al. 2005, 2006). However, more recent research in prostate cancer cell lines has demonstrated that there are three distinct 
classes of androgen-responsive genes, independent of FOXA1, activated by FOXA1 and repressed by FOXA1 (Sahu et al. 2011). Thus, FOXA2 is expected to have a more multifaceted function in the androgen regulation of epididymal gene expression as well. The development of the chromatin immunoprecipitation technology combined with sequencing (ChIP-seq) has enabled genome-wide analyses of actual AR binding to the chromatin. In vivo ChIP-seq studies in mouse caput epididymis demonstrated AR binding to several known ARE sites on epididymal genes. However, the previously published in vitro androgen receptor binding (ARB) data on Lcn5, reproductive homeobox 5 (Rhox5), and cysteine-rich secretory protein 1 (Crisp1) promoter areas was not corroborated in ChIP-seq or ChIP-qPCR experiments, suggesting that these in vitro identified binding sites do not have a biological relevance in vivo (Hu et al. 2010). Moreover, a comparison of ARBs and expression of androgen-regulated genes between three androgen-regulated tissues, prostate, kidney, and caput epididymis, revealed that AR cistromes and respective androgen-regulated transcription patterns are highly tissue specific, and the three tissues shared only $7-16 \%$ of ARBs and only 21 genes were androgen regulated in all tissues (Pihlajamaa et al. 2014). Interestingly, de novo motif analyses showed that transcription factor AP-2 gamma (TFAP2C) binding sites were adjacent to $25 \%$ of ARBs in the epididymis. Further in vivo ChIPseq analyses confirmed TFAP2c binding to those sites. Finally, in vitro experiments in immortalized epididymal epithelial cell line, mE-Cap28, showed that depletion of Tfap2C significantly reduced AR binding to the ARBs shared with AR and TFAP2C. This suggests that TFAP2C may function as a pioneer factor priming the chromatin for subsequent AR binding in the epididymis (Pihlajamaa et al. 2014).

\section{Conclusions}

Due to its highly organized structure and strictly regulated gene expression, the epididymis is an especially suitable model tissue for studying the regulation of gene expression in vivo. Being regulated by endocrine, lumicrine, and paracrine factors, a wide variety of mechanisms can be analyzed in the epididymis. New genome-wide techniques such as ChIP-seq has provided a powerful means for characterizing various aspects of regulation of gene expression and the functional consequences of it. Interestingly, scientific advances during recent years have revealed how intimately different regulatory networks are connected to each other. Steroid hormones regulate miRNA expression, which in turn can regulate steroid hormone signaling either by regulating the levels of steroid receptors or their coregulators or downstream target genes. Interestingly, miRNAs have been suggested to regulate estrogen receptor 1 (Esr 1 ) levels in response to AR activation (Delic et al. 2010), implying a function in maintaining proper balance in androgen/estrogen action in cells. Moreover, epigenetic factors modify androgen receptor activity. DNA methylation affects the accessibility of chromosomal sites for AR binding, whereas a group of AR coregulators possessing histonemodifying activity cause changes in chromatin that affect gene activation/silencing. In addition, histonemodifying enzymes can acetylate/deacetylate AR itself consequently activating/repressing AR transcriptional activity (Matsumoto et al. 2013). The complexity of regulatory networks merits additional studies, and future research will undoubtedly shed light into the regulation of segment-specific gene expression in the epididymis and thus post-testicular sperm maturation.

\section{Declaration of interest}

The authors declare that there is no conflict of interest that could be perceived as prejudicing the impartiality of this review.

\section{Funding}

This research did not receive any specific grant from any funding agency in the public, commercial, or not-for-profit sector.

\section{Acknowledgments}

The authors thank Leena Strauss for critical reading of the manuscript.

\section{References}

Abou-Haila A \& Fain-Maurel MA 1984 Regional differences of the proximal part of mouse epididymis: morphological and histochemical characterization. Anatomical Record 209 197-208.

Belleannee C 2015 Extracellular microRNAs from the epididymis as potential mediators of cell-to-cell communication. Asian Journal of Andrology 17 730-736. (doi:10.4103/1008-682X.155532)

Belleannee C, Calvo E, Thimon V, Cyr DG, Legare C, Garneau L \& Sullivan R 2012a Role of microRNAs in controlling gene expression in different segments of the human epididymis. PLOS ONE 7 e34996. (doi:10.1371/journal.pone.0034996)

Belleannee C, Thimon V \& Sullivan R 2012b Region-specific gene expression in the epididymis. Cell and Tissue Research 349 717-731. (doi:10.1007/s00441-012-1381-0)

Belleannee C, Calvo E, Caballero J \& Sullivan R 2013a Epididymosomes convey different repertoires of microRNAs throughout the bovine epididymis. Biology of Reproduction 89 1-11. (doi:10.1095/biolreprod. 113.110486)

Belleannee C, Legare C, Calvo E, Thimon V \& Sullivan R 2013 b microRNA signature is altered in both human epididymis and seminal microvesicles following vasectomy. Human Reproduction 28 1455-1467. (doi:10.1093/humrep/det088)

Bhardwaj A, Song HW, Beildeck M, Kerkhofs S, Castoro R, Shanker S, De Gendt K, Suzuki K, Claessens F, Issa JP et al. 2012 DNA demethylationdependent AR recruitment and GATA factors drive Rhox5 homeobox gene transcription in the epididymis. Molecular Endocrinology 26 538-549. (doi:10.1210/me.2011-1059)

Björkgren I \& Sipilä P 2015 The role of Dicer1 in the male reproductive tract. Asian Journal of Andrology 17 737-741.

Björkgren I, Saastamoinen L, Krutskikh A, Huhtaniemi I, Poutanen M \& Sipilä P 2012 Dicer1 ablation in the mouse epididymis causes 
dedifferentiation of the epithelium and imbalance in sex steroid signaling. PLOS ONE 7 e38457. (doi:10.1371/journal.pone.0038457)

Björkgren I, Gylling H, Turunen H, Huhtaniemi I, Strauss L, Poutanen M \& Sipilä P 2015 Imbalanced lipid homeostasis in the conditional Dicer1 knockout mouse epididymis causes instability of the sperm membrane. FASEB Journal 29 433-442. (doi:10.1096/fj.14259382)

Blomberg Jensen $M$, Nielsen JE, Jorgensen A, Rajpert-De Meyts $E$, Kristensen DM, Jorgensen N, Skakkebaek NE, Juul A \& Leffers H 2010 Vitamin $\mathrm{D}$ receptor and vitamin $\mathrm{D}$ metabolizing enzymes are expressed in the human male reproductive tract. Human Reproduction 251303 1311. (doi:10.1093/humrep/deq024)

Brinkmeier ML, Geister KA, Jones M, Waqas M, Maillard I \& Camper SA 2015 The histone methyltransferase gene absent, small, or homeotic discs-1 like is required for normal hox gene expression and fertility in mice. Biology of Reproduction 93 1-12. (doi:10.1095/biolreprod.115.130484)

Carninci P, Kasukawa T, Katayama S, Gough J, Frith MC, Maeda N, Oyama R, Ravasi T, Lenhard B, Wells C et al. 2005 The transcriptional landscape of the mammalian genome. Science 309 1559-1563.

Chen Q, Yan M, Cao Z, Li X, Zhang Y, Shi J, Feng GH, Peng H, Zhang X, Zhang Y et al. 2016 Sperm tsRNAs contribute to intergenerational inheritance of an acquired metabolic disorder. Science 351 397-400. (doi:10.1126/science.aad7977)

Chu C, Zheng G, Hu S, Zhang J, Xie S, Ma W, Ni M, Tang C, Zhou L, Zhou Y et al. 2015 Epididymal region-specific miRNA expression and DNA methylation and their roles in controlling gene expression in rats. PLOS ONE 10 e0124450. (doi:10.1371/journal.pone.0124450)

Cutolo M, Seriolo B, Villaggio B, Pizzorni C, Craviotto C \& Sulli A 2002 Androgens and estrogens modulate the immune and inflammatory responses in rheumatoid arthritis. Annals of the New York Academy of Sciences 966 131-142. (doi:10.1111/nyas.2002.966.issue-1)

Dacheux JL \& Dacheux F 2013 New insights into epididymal function in relation to sperm maturation. Reproduction 147 R27-R42. (doi:10.1530/ REP-13-0420)

Darwanto A, Kitazawa R, Mori K, Kondo T \& Kitazawa S 2008 MeCP2 expression and promoter methylation of cyclin D1 gene are associated with cyclin D1 expression in developing rat epididymal duct. Acta Histochemica et Cytochemica 41 135-142. (doi:10.1267/ahc.08025)

Delic D, Grosser C, Dkhil M, Al-Quraishy S \& Wunderlich F 2010 Testosterone-induced upregulation of miRNAs in the female mouse liver. Steroids 75 998-1004. (doi:10.1016/j.steroids.2010.06.010)

ENCODE Project Consortium, Birney E, Stamatoyannopoulos JA, Dutta A, Guigo R, Gingeras TR, Margulies EH, Weng Z, Snyder M, Dermitzakis ET et al. 2007 Identification and analysis of functional elements in 1\% of the human genome by the ENCODE pilot project. Nature 447 799-816.

Fürst RW, Kliem H, Meyer HH \& Ulbrich SE 2012 A differentially methylated single CpG-site is correlated with estrogen receptor alpha transcription. Journal of Steroid Biochemistry and Molecular Biology 130 96-104. (doi:10.1016/j.jsbmb.2012.01.009)

Gregory GD, Vakoc CR, Rozovskaia T, Zheng X, Patel S, Nakamura T, Canaani E \& Blobel GA 2007 Mammalian ASH1L is a histone methyltransferase that occupies the transcribed region of active genes. Molecular and Cellular Biology 27 8466-8479. (doi:10.1128/ MCB.00993-07)

Hammond SM 2015 An overview of microRNAs. Advanced Drug Delivery Reviews 87 3-14. (doi:10.1016/j.addr.2015.05.001)

Heemers HV \& Tindall DJ 2007 Androgen receptor (AR) coregulators: a diversity of functions converging on and regulating the AR transcriptional complex. Endocrine Reviews 28 778-808. (doi:10.1210/er.2007-0019)

Hermo L \& Jacks D 2002 Nature's ingenuity: bypassing the classical secretory route via apocrine secretion. Molecular Reproduction and Development 63 394-410. (doi:10.1002/(ISSN)1098-2795)

Hess RA 2014 Disruption of estrogen receptor signaling and similar pathways in the efferent ductules and initial segment of the epididymis.Spermatogenesis 4e979103-Aug. (doi:10.4161/21565562. 2014.979103)

Hess RA, Fernandes SA, Gomes GR, Oliveira CA, Lazari MF \& Porto CS 2011 Estrogen and its receptors in efferent ductules and epididymis. Journal of Andrology 32 600-613. (doi:10.2164/jandrol.110.012872)

Hu S, Yao G, Guan X, Ni Z, Ma W, Wilson EM, French FS, Liu Q \& Zhang Y 2010 Research resource: genome-wide mapping of in vivo androgen receptor binding sites in mouse epididymis. Molecular Endocrinology 24 2392-2405. (doi:10.1210/me.2010-0226)

Johnson GD, Mackie P, Jodar M, Moskovtsev S \& Krawetz SA 2015 Chromatin and extracellular vesicle associated sperm RNAs. Nucleic Acids Research 43 6847-6859. (doi:10.1093/nar/gkv591)

Koch S, Acebron SP, Herbst J, Hatiboglu G \& Niehrs C 2015 Posttranscriptional Wnt signaling governs epididymal sperm maturation. Cell 163 1225-1236. (doi:10.1016/j.cell.2015.10.029)

Kohli RM \& Zhang Y 2013 TET enzymes, TDG and the dynamics of DNA demethylation. Nature 502 472-479. (doi:10.1038/nature12750)

Krutskikh A, De Gendt K, Sharp V, Verhoeven G, Poutanen M \& Huhtaniemi I 2011 Targeted inactivation of the androgen receptor gene in murine proximal epididymis causes epithelial hypotrophy and obstructive azoospermia. Endocrinology 152 689-696. (doi:10.1210/en.2010-0768)

Landgraf P, Rusu M, Sheridan R, Sewer A, lovino N, Aravin A, Pfeffer S, Rice A, Kamphorst AO, Landthaler M et al. 2007 A mammalian microRNA expression atlas based on small RNA library sequencing. Cell 129 1401-1414. (doi:10.1016/j.cell.2007.04.040)

Li J, Liu Y, Dong D \& Zhang Z 2010 Evolution of an X-linked primatespecific micro RNA cluster. Molecular Biology and Evolution 27 671-683. (doi:10.1093/molbev/msp284)

Li Y, Wang HY, Wan FC, Liu FJ, Liu J, Zhang N, Jin SH \& Li JY 2012 Deep sequencing analysis of small non-coding RNAs reveals the diversity of microRNAs and piRNAs in the human epididymis. Gene 497 330-335. (doi:10.1016/j.gene.2012.01.038)

Ma W, Xie S, Ni M, Huang X, Hu S, Liu Q, Liu A, Zhang J \& Zhang Y 2012 MicroRNA-29a inhibited epididymal epithelial cell proliferation by targeting nuclear autoantigenic sperm protein (NASP). Journal of Biological Chemistry 287 10189-10199. (doi:10.1074/jbc. M111.303636)

Ma W, Hu S, Yao G, Xie S, Ni M, Liu Q, Gao X, Zhang J, Huang X \& Zhang Y 2013 An androgen receptor-microrna-29a regulatory circuitry in mouse epididymis. Journal of Biological Chemistry 288 29369-29381. (doi:10.1074/jbc.M113.454066)

Maris P, Campana A, Barone I, Giordano C, Morelli C, Malivindi R, Sisci D, Aquila S, Rago V, Bonofiglio D et al. 2015 Androgens inhibit aromatase expression through DAX-1: insights into the molecular link between hormone balance and Leydig cancer development. Endocrinology 156 1251-1262. (doi:10.1210/en.2014-1654)

Matsumoto T, Sakari M, Okada M, Yokoyama A, Takahashi S, Kouzmenko A \& Kato S 2013 The androgen receptor in health and disease. Annual Review of Physiology 75 201-224. (doi:10.1146/ annurev-physiol-030212-183656)

Mendive F, Laurent P, Van Schoore G, Skarnes W, Pochet R \& Vassart G 2006 Defective postnatal development of the male reproductive tract in LGR4 knockout mice. Developmental Biology 290 421-434. (doi:10.1016/j.ydbio.2005.11.043)

Murashima A, Miyagawa S, Ogino Y, Nishida-Fukuda H, Araki K, Matsumoto T, Kaneko T, Yoshinaga K, Yamamura K, Kurita T et al. 2011 Essential roles of androgen signaling in Wolffian duct stabilization and epididymal cell differentiation. Endocrinology 152 1640-1651. (doi:10.1210/en.2010-1121)

Nixon B, Stanger SJ, Mihalas BP, Reilly JN, Anderson AL, Dun MD, Tyagi S, Holt JE \& McLaughlin EA 2015a Next generation sequencing analysis reveals segmental patterns of microRNA expression in mouse epididymal epithelial cells. PLOS ONE 10 e0135605. (doi:10.1371/ journal.pone.0135605)

Nixon B, Stanger SJ, Mihalas BP, Reilly JN, Anderson AL, Tyagi S, Holt JE \& McLaughlin EA 2015b The microRNA signature of mouse spermatozoa is substantially modified during epididymal maturation. Biology of Reproduction 93 91. (doi:10.1095/biolreprod.115.132209)

O'Hara L, Welsh M, Saunders PT \& Smith LB 2011 Androgen receptor expression in the caput epididymal epithelium is essential for development of the initial segment and epididymal spermatozoa transit. Endocrinology 152 718-729. (doi:10.1210/en.2010-0928)

Palladino MA \& Hinton BT 1994 Expression of multiple gamma-glutamyl transpeptidase messenger ribonucleic acid transcripts in the adult rat epididymis is differentially regulated by androgens and testicular factors in a region-specific manner. Endocrinology 135 1146-1156.

Pihlajamaa P, Sahu B, Lyly L, Aittomaki V, Hautaniemi S \& Jänne OA 2014 Tissue-specific pioneer factors associate with androgen receptor 
cistromes and transcription programs. EMBO Journal 33 312-326. (doi:10.1002/embj.201385895)

Ribatti D \& Santoiemma M 2014 Epithelial-mesenchymal interactions: a fundamental Developmental Biology mechanism. International Journal of Developmental Biology 58 303-306. (doi:10.1387/ijdb.140143dr)

Robaire B \& Hamzeh M 2011 Androgen action in the epididymis. Journal of Andrology 32 592-599. (doi:10.2164/jandrol.111.014266)

Robaire B, Hinton BT \& Orgebin-Crist MC 2006 The epididymis. In Knobil and Neill's Physiology of Reproduction, 3rd edn, pp 1071-1148. Ed. JD Neill. Boston, MA, USA: Elsevier Inc.

Ross RJ, Weiner MM \& Lin H 2014 PIWI proteins and PIWI-interacting RNAs in the soma. Nature 505 353-359. (doi:10.1038/nature12987)

Sadakierska-Chudy A, Kostrzewa RM \& Filip M 2015 A comprehensive view of the epigenetic landscape part I: DNA methylation, passive and active DNA demethylation pathways and histone variants. Neurotoxicity Research 27 84-97. (doi:10.1007/s12640-014-9497-5)

Saez F, Ouvrier A \& Drevet JR 2011 Epididymis cholesterol homeostasis and sperm fertilizing ability. Asian Journal of Andrology 13 11-17. (doi:10.1038/aja.2010.64)

Sahu B, Laakso M, Ovaska K, Mirtti T, Lundin J, Rannikko A, Sankila A, Turunen JP, Lundin M, Konsti J et al. 2011 Dual role of FoxA1 in androgen receptor binding to chromatin, androgen signalling and prostate cancer. EMBO Journal 30 3962-3976. (doi:10.1038/emboj.2011.328)

Selbach M, Schwanhausser B, Thierfelder N, Fang Z, Khanin R \& Rajewsky N 2008 Widespread changes in protein synthesis induced by microRNAs. Nature 455 58-63. (doi:10.1038/nature07228)

Sharma U, Conine CC, Shea JM, Boskovic A, Derr AG, Bing XY, Belleannee C, Kucukural A, Serra RW, Sun F et al. 2016 Biogenesis and function of tRNA fragments during sperm maturation and fertilization in mammals. Science 351 391-396. (doi:10.1126/science.aad6780)

Shaw G \& Renfree MB 2014 Wolffian duct development. Sexual Development: Genetics, Molecular Biology, Evolution, Endocrinology, Embryology, and Pathology of Sex Determination and Differentiation 8 273-280. (doi:10.1159/000363432)

Silva EJ, Queiroz DB, Rodrigues A, Honda L \& Avellar MC 2011 Innate immunity and glucocorticoids: potential regulatory mechanisms in epididymal biology. Journal of Andrology 32 614-624. (doi:10.2164/ jandrol.111.013565)

Sipilä P, Pujianto DA, Shariatmadari R, Nikkila J, Lehtoranta M, Huhtaniemi IT \& Poutanen M 2006 Differential endocrine regulation of genes enriched in initial segment and distal caput of the mouse epididymis as revealed by genome-wide expression profiling. Biology of Reproduction 75 240-251. (doi:10.1095/biolreprod.105.047811)

Sipilä P, Krutskikh A, Pujianto DA, Poutanen M \& Huhtaniemi I 2011 Regional expression of androgen receptor coregulators and androgen action in the mouse epididymis. Journal of Andrology 32 711-717. (doi:10.2164/jandrol.110.012914)

Straussman R, Nejman D, Roberts D, Steinfeld I, Blum B, Benvenisty N, Simon I, Yakhini Z \& Cedar H 2009 Developmental programming of CpG island methylation profiles in the human genome. Nature Structural \& Molecular Biology 16 564-571. (doi:10.1038/nsmb.1594)

Sullivan R \& Saez F 2013 Epididymosomes, prostasomes, and liposomes: their roles in mammalian male reproductive physiology. Reproduction 146 R21-R35. (doi:10.1530/REP-13-0058)

Tomaszewski J, Joseph A, Archambeault D \& Yao HH 2007 Essential roles of inhibin beta A in mouse epididymal coiling. PNAS 104 11322-11327. (doi:10.1073/pnas.0703445104)

Tomsig JL, Usanovic S \& Turner TT 2006 Growth factor-stimulated mitogen-activated kinase (MAPK) phosphorylation in the rat epididymis is limited by segmental boundaries. Biology of Reproduction $75598-$ 604. (doi:10.1095/biolreprod.106.052399)

Turner TT, Bomgardner D, Jacobs JP \& Nguyen QA 2003 Association of segmentation of the epididymal interstitium with segmented tubule function in rats and mice. Reproduction 125 871-878. (doi:10.1530/ rep.0.1250871)

Turunen HT, Sipilä P, Pujianto DA, Damdimopoulos AE, Björkgren I, Huhtaniemi I \& Poutanen M 2011 Members of the murine Pate family are predominantly expressed in the epididymis in a segment-specific fashion and regulated by androgens and other testicular factors. Reproductive Biology and Endocrinology 9 128. (doi:10.1186/1477-7827-9-128)

Wang H \& Kumar TR 2012 Segment- and cell-specific expression of D-type cyclins in the postnatal mouse epididymis. Gene Expression Patterns 12 136-144. (doi:10.1016/j.gep.2012.01.003)

Wang J \& Ruan K 2010a miR-200c affects the mRNA expression of E-cadherin by regulating the mRNA level of TCF8 during post-natal epididymal development in juvenile rats. Acta Biochimica et Biophysica Sinica 42 628-634. (doi:10.1093/abbs/gmq073)

Wang J \& Ruan K $2010 b$ miR-335 is involved in the rat epididymal development by targeting the mRNA of RASA1. Biochemical and Biophysical Research Communications 402 222-227. (doi:10.1016/j. bbrc.2010.10.002)

Wang H, Walsh ST \& Parthun MR 2008 Expanded binding specificity of the human histone chaperone NASP. Nucleic Acids Research $\mathbf{3 6}$ 5763-5772. (doi:10.1093/nar/gkn574)

Williams K, McKinnell C, Saunders PT, Walker M, Fisher JS, Turner KJ, Atanassova N \& Sharpe M 2001 Neonatal exposure to potent and environmental oestrogens and abnormalities of the male reproductive system in the rat: evidence for importance of the androgen-oestrogen balance and assessment of the relevance to man. Human Reproduction Update 7 236-247. (doi:10.1093/humupd/7.3.236)

Wu X, Zhao B, Li W, Chen Y, Liang R, Li L, Jin Y \& Ruan K 2012 MiR-200a is involved in rat epididymal development by targeting beta-catenin mRNA. Acta Biochimica et Biophysica Sinica 44 233-240. (doi:10.1093/ abbs/gmr122)

Yan Z, Hu HY, Jiang X, Maierhofer V, Neb E, He L, Hu Y, Hu H, Li N, Chen W et al. 2011 Widespread expression of piRNA-like molecules in somatic tissues. Nucleic Acids Research 39 6596-6607. (doi:10.1093/ nar/gkr298)

Yu X, Gupta A, Wang Y, Suzuki K, Mirosevich J, Orgebin-Crist MC \& Matusik RJ 2005 Foxa1 and Foxa2 interact with the androgen receptor to regulate prostate and epididymal genes differentially. Annals of the New York Academy of Sciences 1061 77-93. (doi:10.1196/annals.1336.009)

Yu X, Suzuki K, Wang Y, Gupta A, Jin R, Orgebin-Crist MC \& Matusik R 2006 The role of forkhead box A2 to restrict androgen-regulated gene expression of lipocalin 5 in the mouse epididymis. Molecular Endocrinology 20 2418-2431. (doi:10.1210/me.2006-0008)

Zhang J, Liu Q, Zhang W, Li J, Li Z, Tang Z, Li Y, Han C, Hall SH \& Zhang Y 2010 Comparative profiling of genes and miRNAs expressed in the newborn, young adult, and aged human epididymides. Acta Biochimica et Biophysica Sinica 42 145-153. (doi:10.1093/abbs/gmp116)

Zhang J, Xie S, Ma W, Teng Y, Tian Y, Huang X \& Zhang Y 2013 A newly identified microRNA, mmu-miR-7578, functions as a negative regulator on inflammatory cytokines tumor necrosis factor-alpha and interleukin-6 via targeting Egr1 in vivo. Journal of Biological Chemistry 288 4310-4320. (doi:10.1074/jbc.M112.351197)

Zhou VW, Goren A \& Bernstein BE 2011 Charting histone modifications and the functional organization of mammalian genomes. Nature reviews.Genetics 12 7-18. (doi:10.1038/nrg2905)

Received 9 November 2015

First decision 14 December 2015

Revised manuscript received 11 May 2016

Accepted 23 May 2016 